\title{
A Comparative Study On 136 Opioid Abusers In India and Nepal
}

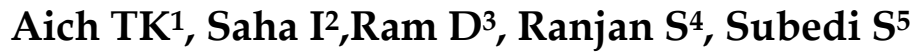 \\ 1.Professor, UCMS, Bhairahawa, Nepal 2. Assistant Professor, KMC, Kolkata, India 3. Assistant Professor, JSS \\ Medical College, Mysore, India 4. Associate Professor, UCMS, Bhairahawa Nepal, 5. Assistant Professor, \\ UCMS, Bhairahawa, Nepal
}

Email Corresponding Address:tapas_dr@yahoo.co.in

\begin{abstract}
Background: Though opioid abuse is a common clinical entity, only few published articles are available in Nepal.

Aim: To compare the pattern of drugs and opioid abuse amongst patients at two de-addiction centres in India and Nepal

Methods: Seventy-six opioid abusers at CIP, Ranchi, India and 60 opioid abusers at UCMS, Bhairahawa, Nepal were recruited for the present study. Demographic and clinical profiles of patients at these two places are studied and compared.

Results: Mean age of patients at Bhairahawa, Nepal was significantly lower than their counterpart in Ranchi. While majority of patients at Ranchi reported alone for treatment, patients at Bhairahawa were mostly accompanied by their guardians/relatives or friends. Patients at Ranchi had more lifetime diagnosis of opioid abuse while patients at Nepal had more lifetime diagnosis of poly-substance abuse. Patients at Bhairahawa, Nepal had significantly more history of Injectable drug abuse and had more history of IDU related side effects. Approximately 40\% of opioid abusers in Nepal centre responded that the opportunity to work abroad was the highest motivating factor for seeking treatment. Opioid withdrawal delirium appeared to a valid clinical entity with history of 5 cases and 2 cases of withdrawal delirium in Ranchi and Bhairahawa center respectively. Symptom of 'Koro' during opioid withdrawal period was reported by at least one patient each at Ranchi and Nepal center.
\end{abstract}

Conclusions: Opioid abusers at both the centres appear to have similar social and clinical characteristics except on few social and clinical parameters.

Key Words: Opioid abuse, Buprenorphine abuse, IDU, Opioid withdrawal delirium, Koro, India, Nepal.

\section{INTRODUCTION}

Global trend among those dependent on drugs is towards the use of multiple psychoactive substances, with people moving from one substance to another, and using drugs in various combinations. ${ }^{1}$. Literature on opioid abuse started appearing by early nineteen-eighties. A number of reports have highlighted the abuse of buprenorphine in oral as well as parenteral forms and alone as well as in combination with benzodiazepines or antihistamines. ${ }^{2,3}$ An excellent update on the buprenorphine abuse in India was given by Sharma and Mattoo. ${ }^{4}$

In Nepal by mid-seventies cases of drug dependency on opiates, especially heroin began to appear. Both official and unofficial estimates indicate that from virtually no cases in 1976, there were over 10000 and even as high as 20,000 heroin addicts a decade later, concentrated in the Kathmandu Valley.5-7 In a socio-psychological study among 393 male injectable drug users in Kathmandu valley, it was found that most frequently used psychoactive substance was injection Buprenorphine, followed by mixture of various substances (opiates, benzodiazepines, antihistamines) and Diacetyl morphine (Brown sugar). ${ }^{8}$ In another study on opioid abusers from the border town Bhairahawa, it was reported that the most characteristic opioid abuse pattern was abuse of brown sugar through inhalation. ${ }^{9}$ Most characteristic buprenorphine abuse pattern seen was an evolution from injection buprenorphine to triple injection to brown sugar abuse.

First author had the unique opportunity to work in two different de-addiction centers in two different 
countries. Present study aims to compare the demographic profile, and the pattern of opioid abuse amongst 136 opioid abusers in India and Nepal.

\section{METHODOLOGY}

It was a clinical study spanning over two deaddiction centers, located in two different countries, within the SAARC region: Central Institute of Psychiatry (CIP) at Ranchi, India and the Universal College of Medical Sciences (UCMS), at Bhairahawa, Nepal. Ethical approval for the study was taken from the institute's 'Ethics approval committee' prior to starting the study. Individual patient's consent was taken before including their clinical data for the present study.

Inclusion criteria were all inpatients within the age range of 15-45 years with a DSM-IV diagnosis of opioid abuse/dependence. ${ }^{10}$ Exclusion criteria were the history of opioid abuse secondary to functional/organic mental illness and mental retardation.

First author worked as a senior resident in a newly built de-addiction center at CIP, Ranchi for a period of 15 months (Oct, 1999 - Jan, 2001). All consecutive cases that were admitted, during the period, with a diagnosis of opioid abuse/dependence and/or polysubstance abuse with predominantly opioid dependence were included for the initial assessment

Patients were re-interviewed and reassessed in the ward, with history clarified from the patients as well as patient's guardians (wherever present), and diagnosis were confirmed according to DSM-IV. DSM-IV questionnaire was used to note down the pattern of drug abuse during last 5 years (lifetime diagnosis) and during last one month (current diagnosis).

In a specially designed data sheet patient's demographic profiles like age, sex, religion and clinical profiles like duration of abuse, amount of abuse, reason for seeking treatment, etc were noted. A total of 76 opioid abusers were included for the study at Ranchi center, who were admitted and treated there during the specified period, and who fulfilled our inclusion and exclusion criteria.

Subsequently first author shifted to a newly established medical college set up (UCMS) in a Indo-Nepal border town at Bhairahawa, Nepal. In addition to a psychiatric set-up, a de-addiction center also made a humble beginning. While treating and observing the patients at UCMS, Nepal it was noticed that the opioid abusers attending our clinic at Nepal have some significant demographic and clinical differences with their counterpart at Ranchi, India.

First opioid abuser was admitted for detoxification in April 2001. By September 2002 (total 18 months), a total of 60 opioid abusers, who received treatment at our center in Nepal and who fulfilled our inclusion and exclusion criteria, were included in the present study for the final analysis.

Thus, for the present study, data received from 136 cases were analyzed. Analysis was done by using simple descriptive statistics like frequency and percentages, Chi-square test and T-test.

\section{RESULTS}

Mean age of patients at Bhairahawa, Nepal were significantly lower than their counterpart in Ranchi, India $\left(\chi^{2}=5.2 ; p=0.009\right)$. Patients, who reported at our center at Bhairahawa, mostly $(93.2 \%)$ came from nearby localities within $50 \mathrm{~km}$ radius. Patients at Ranchi reported themselves to be economically better placed than their Bhairahawa counterpart, who, mostly belonged to low and middle income group.

While majority of patients $(78.9 \%)$ at Ranchi reported alone for treatment, patients at Bhairahawa were mostly accompanied by their guardians/relatives or friends $(76.6 \%)$.

Drug abuse in the two groups did not differ when current pattern of opioid abuse was considered. But, when we analyzed their lifetime pattern of drug abuse, we observed that patients at Ranchi had significantly more lifetime diagnosis of opioid abuse/dependence and patients at Nepal had significantly more lifetime diagnosis of polysubstance abuse/dependence $\left(\chi^{2}=8.4 ; \mathrm{p}=0.004\right)$. 
Table.1: Demographic profiles compared

\begin{tabular}{|c|c|c|c|c|c|c|}
\hline Variable & & $(\mathrm{N}=76)$ & & re $(\mathrm{N}=60)$ & $t / \chi^{2}$ & $\mathbf{P}$ \\
\hline $\begin{array}{l}\text { 1. Age (in yrs.) } \\
\text { 2. Religion } \\
\text { Hindu } \\
\text { Muslim } \\
\text { 3. Nationality } \\
\text { Indian } \\
\text { Nepalese } \\
\text { 4. Locality } \\
\text { Within city area } \\
\text { Within } 50 \mathrm{~km} \text {. } \\
\text { 50-200 km. } \\
\text { Beyond } 200 \mathrm{~km} \text {. } \\
\text { 5. SES } \\
\text { Low/Low-middle } \\
\text { Middle } \\
\text { High/High-middle } \\
\text { 6. First Contact } \\
\text { Alone/groups } \\
\text { With guardians }\end{array}$ & $\begin{array}{r}30.2 \\
67 \\
9 \\
\\
75 \\
1 \\
\\
5 \\
6 \\
26 \\
39 \\
\\
16 \\
48 \\
12 \\
60 \\
16\end{array}$ & $\begin{array}{l}63.2 \% \\
15.8 \% \\
78.9 \%\end{array}$ & $\begin{array}{c}24.8 \\
59 \\
1 \\
5 \\
55 \\
55 \\
34 \\
22 \\
3 \\
1 \\
\\
44 \\
14 \\
4 \\
\\
14 \\
46\end{array}$ & $\begin{array}{l}91.6 \% \\
56.6 \% \\
36.6 \% \\
\\
73.3 \% \\
23.3 \% \\
76.6 \%\end{array}$ & 5.2 & $0.009^{* *}$ \\
\hline
\end{tabular}

**Significant at 0.01 level

Table.2: Clinical profiles compared

\begin{tabular}{|c|c|c|c|c|c|c|}
\hline Variable & $\begin{array}{l}\text { Ranchi centre } \\
(\mathrm{N}=76)\end{array}$ & $\%$ & $\begin{array}{c}\text { Nepal centre } \\
(\mathrm{N}=60)\end{array}$ & $\%$ & $t / \chi^{2}$ & $\mathbf{P}$ \\
\hline $\begin{array}{l}\text { 1.Lifetime diagnosis } \\
\text { Opioid abuse/dependence } \\
\text { Poly-substance abuse }\end{array}$ & $\begin{array}{l}39 \\
37\end{array}$ & $\begin{array}{l}51.3 \\
48.7\end{array}$ & $\begin{array}{l}16 \\
44\end{array}$ & $\begin{array}{l}26.6 \\
73.4\end{array}$ & 8.4 & $0.005^{* *}$ \\
\hline $\begin{array}{l}\text { 2. Current diagnosis } \\
\text { Opioid abuse/dependence } \\
\text { Poly-substance abuse }\end{array}$ & $\begin{array}{l}57 \\
19\end{array}$ & $\begin{array}{l}75 \\
25 \\
\end{array}$ & $\begin{array}{l}43 \\
17\end{array}$ & $\begin{array}{l}71.6 \\
28.4\end{array}$ & 0.2 & 0.6 \\
\hline 3. Duration of abuse (yrs.) & 5.9 & $\mathrm{SD}=4.2$ & 2.8 & $\mathrm{SD}=2.3$ & 4.9 & $0.000^{* * *}$ \\
\hline $\begin{array}{l}\text { 4. Pd. Of hospitalisation } \\
\text { (in days) }\end{array}$ & 12.3 & $\mathrm{SD}=7.8$ & 8.3 & $\mathrm{SD}=5.6$ & 3.2 & $0.005^{* *}$ \\
\hline $\begin{array}{l}\text { 5. H/o Inj. Drug use (IDU) } \\
\text { Present } \\
\text { Absent }\end{array}$ & $\begin{array}{l}11 \\
65\end{array}$ & 14.5 & $\begin{array}{l}26 \\
34 \\
\end{array}$ & 43.3 & 14.1 & $0.000^{* * *}$ \\
\hline $\begin{array}{l}\text { 6. Thrombophlebitis } \\
\text { Present } \\
\text { Absent }\end{array}$ & $\begin{array}{l}3 \\
73\end{array}$ & 3.9 & $\begin{array}{l}16 \\
44\end{array}$ & 26.6 & 14.4 & $0.000^{* * *}$ \\
\hline $\begin{array}{l}\text { 7. Follow-up } \\
\text { None } \\
\text { Once } \\
\text { Twice or more }\end{array}$ & $\begin{array}{l}61 \\
13 \\
2\end{array}$ & $\begin{array}{l}80.3 \\
17.1\end{array}$ & $\begin{array}{l}40 \\
9 \\
11\end{array}$ & 66.6 & 9.5 & $0.008^{* *}$ \\
\hline $\begin{array}{l}\text { 8. Readmission } \\
\text { Yes } \\
\text { No }\end{array}$ & $\begin{array}{l}15 \\
60\end{array}$ & 19.7 & $\begin{array}{l}6 \\
54\end{array}$ & 10 & 2.4 & 0.2 \\
\hline
\end{tabular}

*Significant at 0.05 level, **Significant at 0.01 level, ***Significant at 0.001 level 
Table.3: Pattern of evolution of opioid abuse

\begin{tabular}{|c|c|c|c|c|}
\hline \multirow[t]{2}{*}{ Pattern of abuse } & \multicolumn{2}{|c|}{ Ranchi center } & \multicolumn{2}{|c|}{ Nepal center } \\
\hline & $(\mathrm{N}=76)$ & $\%$ & $(\mathrm{~N}=60)$ & $\%$ \\
\hline Cannabis $\longrightarrow$ Opioid & 9 & 11.8 & 0 & 0 \\
\hline $\begin{array}{l}\text { Cannabis } \longrightarrow \text { Opioid } \\
\text { Alcohol }\end{array}$ & 10 & 13.2 & 2 & 3.3 \\
\hline Phensedyl $\longrightarrow$ Opioid & 0 & 0 & 8 & 13.3 \\
\hline Phensedyl $\longrightarrow$ Opioid & 1 & 1.3 & 4 & 6.7 \\
\hline $\begin{array}{l}\text { Phensedyl } \longrightarrow \text { Opioid } \\
\text { Nitrazepam }\end{array}$ & 1 & 1.3 & 7 & 11.7 \\
\hline Nitrazepam $\longrightarrow$ Opioid & 2 & 2.6 & 4 & 6.7 \\
\hline Alcohol $\longrightarrow$ Opioid & 7 & 9.2 & 6 & 10 \\
\hline $\begin{array}{l}\text { Alcohol } \longrightarrow \text { Opioid } \\
\text { Nitrazepam }\end{array}$ & 3 & 3.9 & 2 & 3.3 \\
\hline $\begin{array}{l}\text { Multi drug } \longrightarrow \text { Opioid } \\
\text { Abuse }\end{array}$ & 4 & 5.2 & 11 & 18.3 \\
\hline Pure opioid abusers & 36 & 47.4 & 16 & 26.7 \\
\hline
\end{tabular}

had significantly longer duration of history of opioid abuse $\left(\chi^{2}=4.9 ; \mathrm{p}=0.000\right)$ and they had longer mean duration of hospital stay $\left(\chi^{2}=3.2 ; p=0.005\right)$.

Patients at Bhairahawa, Nepal had significantly more history of Injectable drug abuse $\left(\chi^{2}=14.1\right.$; $\mathrm{p}=0.000)$, had more history of IDU related side effects like thrombophlebitis $\left(\chi^{2}=14.4 ; p=0.000\right)$.

We see that pure opioid abusers were only $26 \%$ of total abusers in Nepal while Ranchi center witnessed more pure opioid abusers (47.4\%).

Most of these patients, in either center, evolved through abuse of other drugs during their journey through 'Royal road to Opioid!'. While history of Cannabis abuse (25\%) and alcohol abuse (27.5\%) was more significantly present amongst opioid abusers in Ranchi, Phensedyl abuse (31.6\%) and Nitrazepam (21.7\%) was more commonly reported

Table.4: Reasons to seek treatment (as reported by our patients at Nepal center):

\begin{tabular}{|ll|}
\hline 1. & To resolve marital conflict \\
2. & Facing financial difficulties \\
3. & Face-off with law enforcing authorities \\
4. & Resolve to lead a decent life \\
5. & Have had enough of it \\
6. & Need for social acceptance \\
7. & Frequent physical illness \\
8. & Opportunity to work abroad \\
9. & Other \\
\hline
\end{tabular}

Twenty-four out of $60(40 \%)$ treatment seekers in Nepal Centre responded that the opportunity to 
work abroad was the highest motivating factor for seeking treatment.

\section{DISCUSSION}

Upadhayaya reported socio-demographic profile of psychoactive substance users in Pokhara valley ${ }^{11}$. UNODC published a study on profile, drug abuse pattern, risk behaviour of women drug users in seven sites in Nepal ${ }^{12}$. Nirula et al revealed, in a paper, that the level of education, occupation and depression were the strong predictors associated with drug abuse ${ }^{13}$.

Details of the findings of the patient group who attended our Bhairahawa center has already been reported and published elsewhere ${ }^{9}$. Preliminary findings of the present paper were presented earlier in a conference ${ }^{14}$. This is a humble attempt in comparing two groups of opioid abusers that was observed in two different set up, in two different countries, within SAARC region.

A. Demographic profiles: Treatment seekers in Nepal were on the average 5 years younger than their counterpart in Ranchi, at the time of their first contact with us. They mostly (93.3\%) came from a nearby urban locality of $50 \mathrm{~km}$ radius. Majority of them were accompanied by their parents/spouse/relatives - who were actively involved in the treatment process.

The typical profile of a buprenorphine abuser that has been reported commonly in the literature is that of an urban, young to middle age (19-42 years) male, who has had some school or college education and, has a low to middle level occupation 8,11,13,15-17. Female opioid abusers are rarely reported in literature ${ }^{12}$.

\section{B. Pattern of opioid abuse}

More patients attending our Nepal center followed 'royal road to opioid': from nicotine via alcohol, cough syrup, cannabis, sedatives to opioid abuse. Most characteristic opioid abuse pattern was that of abuse of brown sugar through inhalation (chasing). While twenty-six (43.3\%) patients in Nepal had history of injection buprenorphine abuse (IDU) only $14.5 \%$ patients in Ranchi had history of IDU- either as a current abuse pattern or with a history of IDU in the past (Table no 2). Abuse of buprenorphine alone was reported in $13-54 \%$ cases by various authors in the past ${ }^{18-20}$.

Most popular pattern of IDU, at our Nepal center, was that of injectable cocktail of triple drug:
Injection Tidigesic (buprenorphine), Injection Diazepam and Injection Hydrocortisone. Outcome of long duration of IDU in this patient population was that they developed thrombophlebitis, acute and chronic infections, HIV positivity, and finally AIDS. Correlates of injecting drug abusers in various parts of Nepal has also been studied and reported by few other authors in the recent past ${ }^{21-23}$.

Lifetime history of cannabis abuse was common amongst patients attending Ranchi center. Lifetime history of Phensedyl abuse was common amongst patients attending Nepal center. Nitrazepam and alcohol was a common add-on drug to brown sugar abuse, to the patients at both the center.

Current level of multi-drug abuse was more common in patients attending Nepal clinic, indicating, perhaps some inadequacy, instability and persistent novelty seeking behaviour in this patient population. This instability in personality was also reflected in more cases of abuse/suspected abuse in the ward, more cases of absconding from ward, more instance of breaking hospital rules and regulations and confrontation with hospital staffs in Nepal Centre. Current level of opioid abuse was more common in patients attending Ranchi clinic perhaps indicating some sort of stability in their drug abuse behaviour, after a long history of drug abuse.

\section{Narrative of an opioid abuser (wordings are} mostly kept unchanged):

On few common and exotic abuse patterns he had experienced in life, reported while receiving treatment with us at Bhairahawa, Nepal.

1. Marijuana mix: First of all cut all the branches of Marijuana and then press it by the help of hand. Then the slippery substance sticks in the hand. Then filter off the matter in the paper and mix it with tobacco of cigarette and feel the depth of Marijuana (Ganja).

2. Handiplast mix: Stick the handiplast at the bottom of the filter of cigarette and take the puff as usual.

3. Using the tail of lizard: First of all, cut off the tail of lizards and dry it up about 3-4 days, then make its powder and mix it with tobacco and take the puff.

4. Using dirty shocks: The dust particles attached at the bottom of shocks are filtered down on the paper, then mix up with 
tobacco and take the puff.

5. Poland mix: It is the purest form of Marijuana. It is found in the form of tablets and imported from foreign. First of all, put the tablet over the paper (Aluminum foil) of cigarette and burnt it over the candle. The smoke that comes is diverted towards the pipe of a rupee note. (So as) not to put any marks over the teeth, put one coin inside the mouth and take the puff.

6. Iodex mix: Using the Iodex over the tobacco and dry up and take the puff.

7. Total dry up Marijuana: It is found in the form of dust powder. It has got different types, like Gold, Black, Pale Yellow, the trip (Depth), rating of different Marijuana are taken respectively. First of all filter up all the unnecessary matters and mix it with tobacco and take the puff.

8. General addictions that I have used except above ones are: Syringe, Nitrogen (Nitrosun) tablets/Sleeping tablets, Fencidyle (Phensedyl) syrup, Purified wine (local), Brown sugar, etc.

Now, totally I left all above except cigarette. Thanks

Mr PP, MA.

Teacher

Tamghas, Gulmi maintain his abstinence from brown sugar! One case report on 'Koro' as withdrawal symptom of opioid is available in literature ${ }^{26}$.

Snake bite as a form of abuse: As least two opioid abusers in Ranchi reported to resort to nonpoisonous snake bite as an additional means of drug abuse, in addition to different types of drugs of abuse that has already been narrated in this article. Bites were taken mostly on the tip of tongue, and said to have a longer 'kick' for these patients! 'Snake bite' as a form of drug abuse is a rarely reported form of abuse ${ }^{27,28}$.

\section{CONCLUSION}

Opioid abusers at both centers were seen to be experimenting with various other drugs before finally sticking to various forms of opioids as a substance of abuse. Current level of brown sugar abuse was commoner at Ranchi Centre, while polysubstance abuse pattern was more characteristically seen at Bhairahawa, Nepal Centre. Patients who attended our Nepal Centre were more impulsive and novelty seeking young male abusers, with history of more injection drug abuse (IDU) and subsequent injection related side effects. 'Snake bite' as a form of drug abuse is probably a rare form of abuse. Opioid withdrawal state presenting as withdrawal delirium and withdrawal 'Koro' are also rarely reported in literature.

\section{REFERENCES}

1. The World Health Report. Comparing suffering, enriching humanity. World Health Organisation, Geneva, 1998.

2. Strang J. Abuse of buprenorphine. Lancet 1985; 2:725.

3. O'Connor J, Maloney E, Travers R. et al. Buprenorphine abuse among opiate addicts. $\mathrm{Br} \mathrm{J}$ Addiction 1988; 83: 1085-87.

4. Sharma Y, Mattoo SK. Buprenorphine abuse in India - an update. Indian J Psychiatry 1999; 41:1529.

5. Shrestha NM. Alcohol and drug abuse in Nepal. Br J Addict 1992; 87 (9): 1241-8.

6. Bhandari B, Subba C. Students and Drugs in Nepal. Kathmandu: Drug Abuse Prevention Association Nepal 1992.

7. Jutkowitz JM, Spielmann $H$, Koehler $U$, et al. A. Drug use in Nepal: The view from the street. Substance use misuse 1997; 32 (7\&8): 987-1004.

8. Ojha SP, Pokhrel P, Acharya RP, Pandey KR, Bhusal CL, Marhatta MN. Socio-psychological study among injectable drug users in Kathmandu valley. J Nepal Med Assoc 2002;41:235-40. 
9. Aich TK, Dhungana M, Khanal R. Pattern of buprenorphine abuse amongst opioid abusers in Nepal. Indian J Psychiatry 2010; 52 (3):250-3.

10. American Psychiatric Assocation (APA). Diagnostic and Statistical Manual of Mental Disorders, $4^{\text {th }}$ ed. (DSM-IV), Washington DC: APA; 1994.

11. Upadhayaya KD. Socio-demographic profile of psychoactive substance users in Pokhara Valley. J Nep Med Assoc 2000; 39: 332-7.

12. UNODC. Profile, Drug abuse pattern, risk behavior and selected bio-markers of women drug users from seven sites in Nepal. UNODC, 2007.

13. Nirula SR, Chhetry DB, Singh GK, Nagesh $S$, Shyangwa PM. Risk factors for drug abuse among Nepalese samples selected from a town of Eastern Nepal. Intl J Ment health Addict 2009; 7(3): 430-40.

14. Aich TK, Dhungana M. Pattern of Drug Abuse amongst 136 Opioid Abusers in India and Nepal. Paper presented at the 55th Annual Conference of Indian Psychiatric Society (ANCIPS), Hyderabad. January 2003.

15. Singh RA, Mattoo SK, Malhotra A, et al. Cases of buprenorphine abuse in India. Acta Psychiatr Scand 1992; 37:23-5.

16. Chowdhury AN, Chowdhury S. Buprenorphine abuse: report from India. Br J Addiction 1990; 85: 1349-50.

17. Umesh Babu SB, Chaturvedi SK. Changing patterns of opiate abuse with a focus on buprenorphine. Indian J Psychiatry 1995; 37(Suppl): 23.

18. De La Fuente L, Barrio G, Royuela L, et al. The transition from injecting to smoking heroin in three Spanish cities. Addiction, 1997; 92: 1749-63.
19. Gupta DK, Desai NG, Chandiramani K. et al. Pattern of multiple substance use in heroin dependent individuals. Indian J Psychiatry 1996; 38(Suppl): 82.

20. Vinay K, Singh BK. Reasons behind increasing buprenorphine abuse. Indian J Psychiatry 1996; 38(Suppl): 82.

21. Shrestha N. Drug injecting practice among adolescents in Pokhara, Sub-metropolitan City, Nepal. JHAS 2012; 2(1): 7-10.

22. Poudel KC, Poudel TK, Yasuoka J, Joshi AB, Jomba $M$. Correlates of sharing injection equipment among male injecting drug users in Kathmandu, Nepal. Int J Drug Policy 2010; 21(6); 507-10.

23. Pradhan SN, Sharma SC, Shrestha MR, Shrestha S. A study of depression among patients with substance use disorder. J Kathmandu Med College 2012; 1(2): 96-99.

24. Parkar SR; Seethalakshmi R; Adarkar S et al: Is this "complicated" opioid withdrawal? Indian J Psychiatry 2006; 48:121-122.

25. Aggarwal A, Choudhary S, Jiloha RC. Opioid Withdrawal Delirium. J Neuropsychiatry Clin Neurosci 2011;23, 4: E37.

26. Chowdhury, A.N. Banerjee, G. Recurrent koro in repeated intravenous buprenorphine withdrawal. Addiction 1996; 91, 145-7.

27. Pradhan $P V$, Shah $L P$, Ghodke PR, Nayak PR. Snake venom habituation in heroin (brown sugar) addiction: (report of two cases). JPGM 1990; 36 (4): 233-4.

28. Katshu MZ, Dubey I, Khess CRJ, Sarkhel S. Snake bite as a novel form of substance abuse: personality profiles and cultural perspectives. Subst Abus. 2011 Jan;32(1):43-6. 